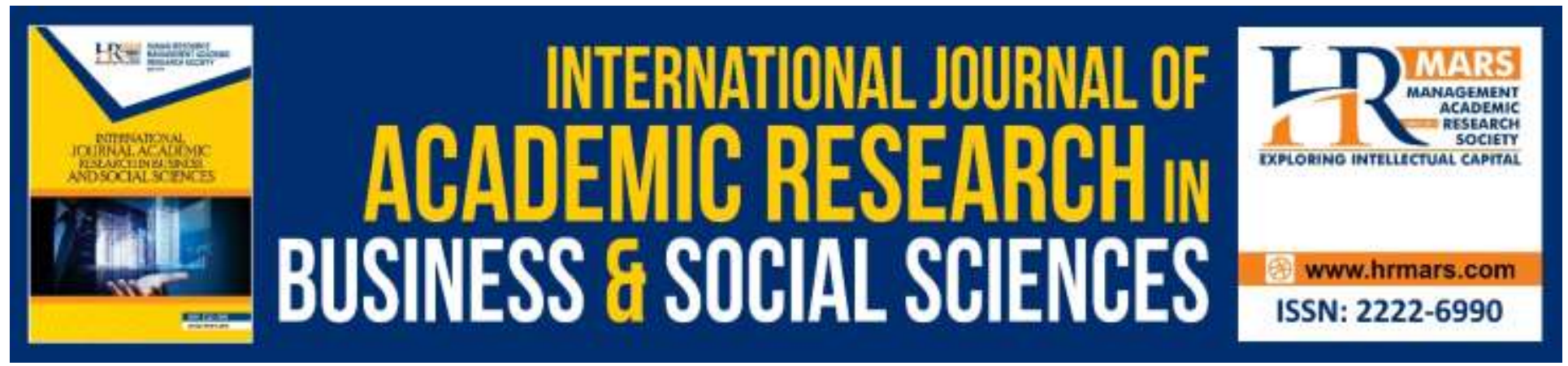

\title{
Big Data Management for Malaysian Small Medium Enterprise (SME) Industries Involving Dust Explosion Incidents
}

Mohd Azimie Bin Ahmad, Norazura Binti Ismail, Mohamad Rizza Bin Othman

To Link this Article: http://dx.doi.org/10.6007/IJARBSS/v9-i11/6648

DOI: 10.6007/IJARBSS/v9-i11/6648

Received: 12 October 2019, Revised: 30 October 2019, Accepted: 03 November 2019

Published Online: 24 November 2019

In-Text Citation: (Ahmad, Ismail \& Othman, 2019)

To Cite this Article: Ahmad, M. A. B., Ismail, N. B., \& Othman, M. R. B. (2019). Big Data Management for Malaysian Small Medium Enterprise (SME) Industries Involving Dust Explosion Incidents. International Journal of Academic Research in Business and Social Sciences, 9(11), 1201-1212.

Copyright: (C) 2019 The Author(s)

Published by Human Resource Management Academic Research Society (www.hrmars.com)

This article is published under the Creative Commons Attribution (CC BY 4.0) license. Anyone may reproduce, distribute, translate and create derivative works of this article (for both commercial and non-commercial purposes), subject to full attribution to the original publication and authors. The full terms of this license may be seen

at: http://creativecommons.org/licences/by/4.0/legalcode

Vol. 9, No. 11, 2019, Pg. 1201 - 1212

http://hrmars.com/index.php/pages/detail/IJARBSS

JOURNAL HOMEPAGE

Full Terms \& Conditions of access and use can be found at http://hrmars.com/index.php/pages/detail/publication-ethics 


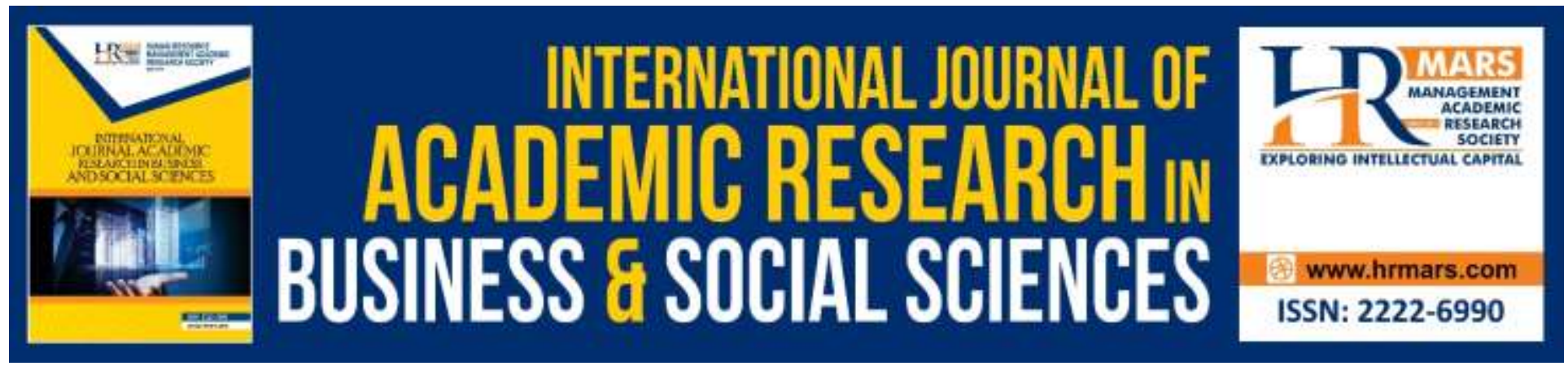

\title{
Big Data Management for Malaysian Small Medium Enterprise (SME) Industries Involving Dust Explosion Incidents
}

\author{
Mohd Azimie Bin Ahmad', Norazura Binti Ismail², Mohamad Rizza \\ Bin Othman ${ }^{3}$
}

Faculty of Engineering Technology, University Malaysia Pahang ${ }^{1,2}$, Faculty of Chemical \& Natural Resources Engineering, University Malaysia Pahang ${ }^{3}$, Malaysia

\begin{abstract}
A dust explosion accident in Malaysia is seldom discussed by the safety practitioner or by authorities. Small Medium Enterprise (SME) industries tend to neglect the risk lies within their boundary since it was not happening, and this mainly become the reason the dust explosion event does occur repeatedly. The introduction of the trend cases in this study will be the goal in order to make industries aware the dust explosion as thread in the business operation sustainability. Data was collected through literature, case reported in DOSH website safety alert, document analysis and observation at field by using triangulation methodology in qualitative research model. It was found out there is an increasing trend in the reported cases related to dust explosion at workplace. This trend does confirm the study that dust explosion accident is becoming threat in making industry to operate in sustainable manner. Nevertheless, in Malaysia, there is still lack of awareness in understanding dust explosion accident by industrial practitioner. This is where the researcher has started an initiative in developing a local database using Microsoft Access comprising all over the world cases study. The compilation of accidents was extracted using five elements related to the Explosion Pentagon principles that will ease industrial sharing in term of lesson learn and this database known as UMP-DEx. This database is maintained by UMP researchers in Process Safety Management. The update takes place throughout years and the sharing on the best practices will be ongoing basis. The normal platform used in developing awareness in industrial is by participating in conferences, project paper publications, journal publications, and lastly by conducting training in industries. The sharing of this database will help industries in managing the same risk from happening by understanding the root cause and easily plan mitigation action to avoid this accident from happened again. Keywords: Dust Explosion, Thread, Sustain, Operation, Trend, Triangulation, Lesson Learned
\end{abstract}




\section{Introduction}

Small Medium Enterprise (SME) in Malaysia brings more than 40\% GDP contribution in year 2017 alone. There is manufacturing that involves with combustible dust in their daily processes such as food processing industries, wood industries, flour industries, sugar factories and many more. The recent accident in Malaysia has recorded several cases involving the dust explosion scenario and bring new thread towards the industry that manages the combustible dust materials. The combustible dust materials handling in the industry have to be the most activity that highlighted to be the point where the possible cause of the explosion to take place. In 2017, November 11, IGB Industrial Estate, plywood manufacturer experienced an explosion accident at their silo, resulting with property damage and causing two (2) burn injuries to the local firefighters situated at Ipoh, Perak, in Malaysia.

Works by Abbasi and Abbasi in 2007; Amyotte and Eckhoff in 2010 have highlighted the potential industries with dust explosions hazard which comprising wood processing and storage including paper products. Another possible industry involves grain and foodstuffs material and equipment such as grain dust, flour and feed mill, bucket elevators, bin and silos, metal manufacturing, fabrication and storage of metals powders and dust. Power generation which deals with pulverized coal, wood and peat also in risk. Other than this, chemical production and process industries such as pesticides, dyes and paints; plastic or polymer production and processing also be considered. Food production, processing and storage including sweetener product, starch and spices. Textile manufacturing and processing such as wool, linen flax and cotton also at risk. Last but not list is pharmaceutical processing plants.

\section{Literature Review}

Previous work was done by experiment on past accident analysis by Abdolhamidzadeh, Abbasi, Rashtchian \& Abbasi 2010; Lees, 2005. The difference in most framework done have to develop foundation for building, testing and defining theoretical framework, there is the very limited scope of conducting research in the domain of accident forecasting and formulation of prevention.

Nevertheless, the past accident analysis needs to be carried out due to the importance of managing industrial accident in chemical process industries (CPI). Proper construction of event, identifying the trigger factor, and study the sequences, and most affected are the consequences. The industry in chemical manufacturing cannot withstand the repetitive accident to take place due to the same trigger. Several hints have been shared through an industry where strategies in accident prevention can be drawn (Khan \& Abbasi, 1998, 1999).

The past accident analysis always has daunting problems associated with the process of getting records of past accident (Abdolhamidzadeh et al., 2010). There are few more to be discussed by the researcher while conducting study in defining framework of the accident analysis which includes:

a) Lack of mechanism in accident reporting and archiving the record in Malaysia

b) Intentional under-reporting of accidents by industries/governments to reduce or escape liability and protect the company reputation 
c) Conflict version of what happened and the inability to have postmortem in order to resolve the uncertainty due to unavailability of evidence.

d) Vague documentation of sequence of accident that takes place

e) Sustain imprecision of available record- as example fire and explosions cases are often recorded in the generic sense and in many situations, it is not possible to figure out the specific event categories.

There are most well-known among paid database which called MHIDAS. It was quoted several times by various researchers in this field. Most researchers that conduct past accident analysis may refer and rely on MHIDAS (Carol, Vilchez, \& Casal, 2002; Clini, Darbra, \& Casal, 2010; Gerboni \& Salvador, 2009; Gomez-Mares, Zarate, \& Casal, 2008; Guo, 2002; Montiel, Vílchez, Arnaldos, \& Casal, 1996; Planas-Cuchi, Montiel, \& Casal, 1997; Renni, Krausmann, \& Cozzani, 2010). But the coverage still not reflecting the industry threat in Malaysia, that the main reason the database UMP-DEx was established in order to cater the need of analysis in Malaysia culture and trend referring to dust explosion in specific.

MHIDAS do cover big scope of process incident, meanwhile UMP-DEx database simply consists of dust explosion accident phenomena in specific. The several categories were tabulated in UMP-DEx database which covers:

a) Type of machine (Malaysia and Oversea trend)

b) Type of dust involves (Malaysia and Oversea trend)

c) Total damage lost due to accident (Malaysia and Oversea trend)

d) The trend from the process industry (Malaysia and Oversea trend)

e) Lesson learnt sharing via accident report (Reference CSB, DOSH website)

\section{Sources of Data}

The idea in this database relies on the assimilation of data from numerous open sources, journal, CSB website, DOSH website and consist of industry sharing cases. Almost 2000 data was tabulated consist of process safety incident, but nearly 200 cases are related in dust explosion was further derived in the UMP-DEx database.

The journal sorting was done in Mendeley software. Management of trend data via metaanalysis easily can be done. Several journals form different publisher was crossed checked in making sure the accident data discussion was not the false cases in order to avoid confusion.

\section{Type of Trigger}

The type of trigger was derived from FM Global analysis in 2014 conference involving insurance industries that cover chemical industries in threat with dust explosion incidents which is:
i. Electricity
ii. Sources of spark/static charge
iii. Hot work activity
iv. Process/equipment failure 
These are the prominent trigger that always causing fire and explosion accident if the proper job delivery was not carried out properly.

\section{Type of Installation}

The installation in this research are defined to be:

i. Machine

ii. Dust Control equipment

iii. Reactor

iv. Conveyor system

v. Piping / ducting

\section{Dust Substances Involved}

The combustible dust is defined in this material comprising of:

i. Polymer dust

ii. Chipboard dust

iii. Metal dust

iv. Flour dust

v. Wooden dust

vi. Sugar and sweetener

vii. Powder types of raw materials

\section{Methodology}

\section{Data Collection Procedure}

The recent work by the researcher has gone through industrial area at Pahang and Terengganu area which is comprising several types of manufacturing also involving the handling of raw materials or product in dust form that is combustible. The said industry is polymer powder manufacturer situated at Gebeng Industrial area, electronic manufacturing using epoxy resin coating for their magnetic insulation material at Pekan Industrial Park, and amino acid feedstock manufacturer from Korea in Kertih Industrial Park.

The session more toward sharing recent work in the development of dust explosion phenomena in one access database handled by University Malaysia Pahang (UMP). A sampling of workplace was done via inspection and interview with the HSE personnel and involving their site worker. The interview session was carried out to confirm the possible condition in the workstation that may lead to the possibility. This session also shared the researcher effort on the development of database knows as UMP-DEx comprising of recent data on dust explosion.

Sharing of lesson learnt was done via communication with the EHS department in the organization and involving training with the staff handling dust environment in their workplace. The accident was briefed throughout the session and question and answer between researcher and participant was carried out. 
The database cover accidents and accident in the petrochemical, chemical, food processing, metal and grain, flour processing industry and many more from the period of 1997 to December 2017. Registered events comprise of worldwide cases and include Malaysia cases.

The collection of complete dust explosion accident list was prepared by doing crosschecked in the different information sources such as journals, DOSH website, CSB website, case studies, and industries sharing. This allowed obtained the necessary information related to the incident, the date, the location, the equipment and the cause and brief description of the event.

Based on these data and using selective keywords, a generic search all over the web and specific search in local newspaper were carried out. Accident data were obtained by reading and extracting data through newspaper articles, institutional reports and journal publication from several publishers.

The study conducted in triangulation method consists of the interview session, survey and site verification. During the study the interview and survey were done via sampling basis.

\section{Results and Discussion}

In an attempt at improving the situation, the authors have developed an access database named University Malaysia Pahang Dust Explosion Database. To put the UMP-DEx database in demand, it may fruitful to measure the strengths and the weakness of the existing database.

\section{The Relevant of UMP-DEx Database in Managing Record of Dust Explosion Incident}

All important question must be addressed at this stage: does UMP-DEx database contain all relevant data related to Dust Explosion incident. Nevertheless, the initiative has started in developing a database handled by UMP that close to industry area in Pahang. The need will come after since the directories will be updated from time to time based on the information gathered from authorities, media and industries themselves.

\section{Overview from Malaysia Situation}

According to Department of Safety and Health (DOSH), from March 2008 until August 2013, there have been five (5) combustible dust explosion incidents resulting seven (7) fatalities and twelve (12) injuries. However, only 3 incidents were published on the DOSH website. The case cited on 12 June 2016.

The above-mentioned cases are grain storage and milling plant situated at Lumut, Perak. The accident takes place on March 17, 2008 involving grain dust explosion where the outcome with 4 dead and 2 injured.

The second case summarized in the website was derived. The accident takes place in Pulau Pinang at motorcycle rim manufacturing factory on March 2010. The case classified as aluminium dust explosion were injured 8 peoples and caused damage to the building, manufacturing plant, dust collector system and broke the windows of nearby factories.

Meanwhile, third case classified as stearate based chemical explosion. It happened in 2013. The industry is medicine and cosmetic processing plant. The exact place was not stated and as the consequences two (2) are dead and two (2) more are severely injured. 
Accessing from the trend in Malaysia, past accident database will play bigger role in developing process safety professional. It is very important to start an effort by all mean to ensure proper and complete documentation of accidents which occur in the process industry. In Malaysia, as developing country it can be achieved by regulating a law to embed it into practice and compliance.

For now, especially, we need to make whatever has been documented and learn to minimize the uncertainty associated with the past records by seeking collaborative evidence from multiple sources and verified it with sharing to industry.

\section{Access to UMP-DEx database}

Currently, the access database was used. The development of an online database and android apps are in consideration. The current database only accessible for training purposes that will highlight all lesson learnt by the researchers. In near future, this web will be available for users to post their lesson learnt case or new materials related to dust explosion accidents.

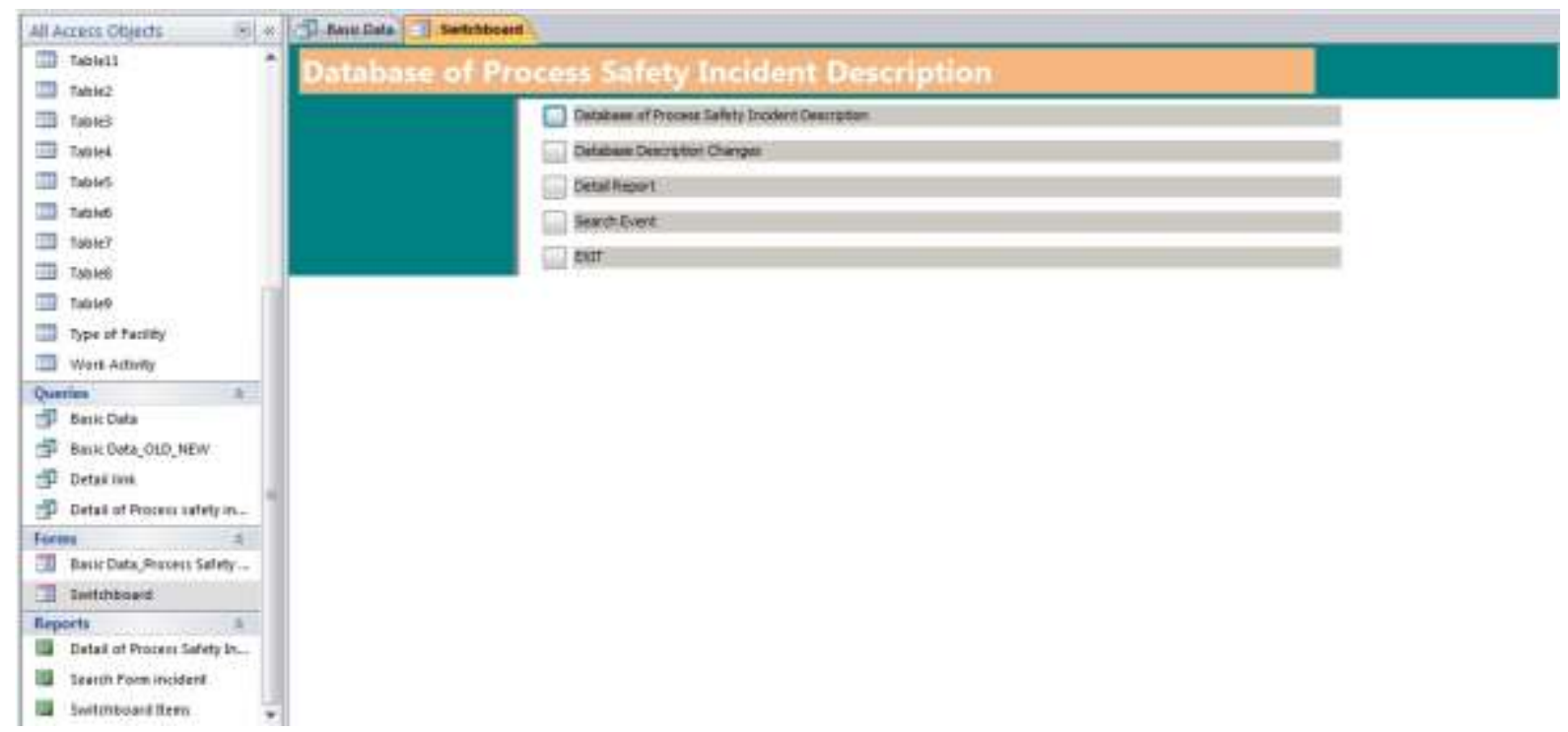

Figure 1: Database interface 
INTERNATIONAL JOURNAL OF ACADEMIC RESEARCH IN BUSINESS AND SOCIAL SCIENCES

Vol. 9, No. 11, November, 2019, E-ISSN: 2222-6990 @ 2019 HRMARS

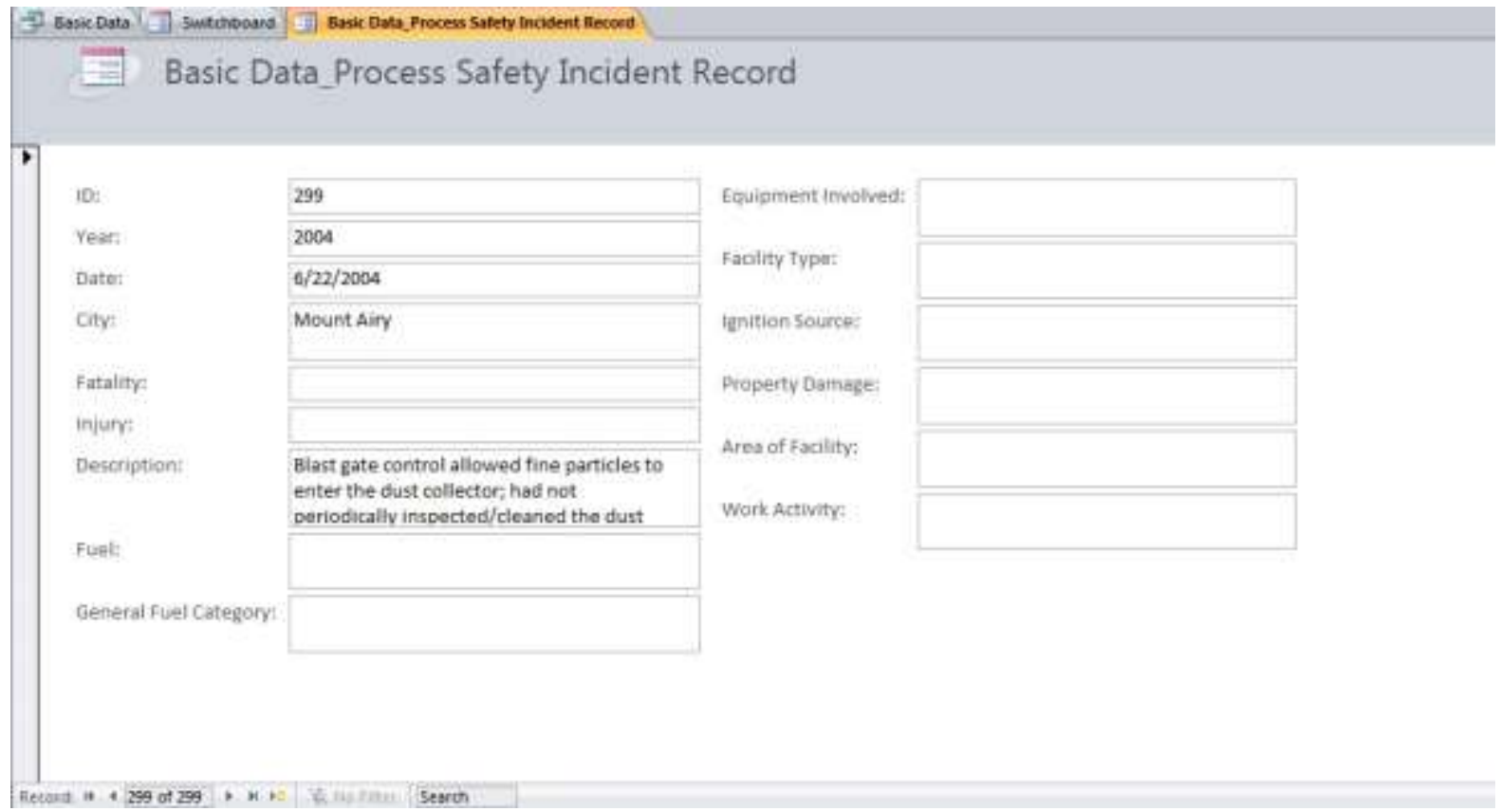

Figure 2: Basic data key in the interface

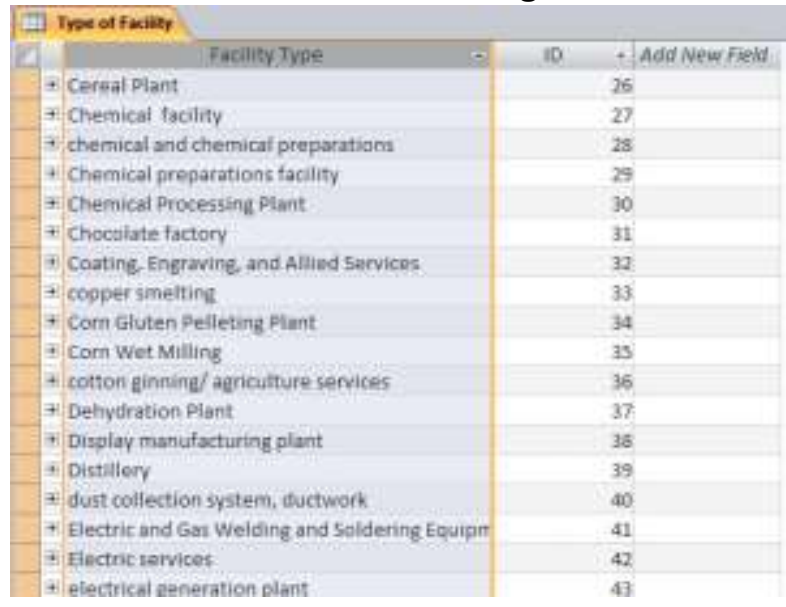

Figure 3: Facility Types Summary 
INTERNATIONAL JOURNAL OF ACADEMIC RESEARCH IN BUSINESS AND SOCIAL SCIENCES

Vol. 9, No. 11, November, 2019, E-ISSN: 2222-6990 @ 2019 HRMARS

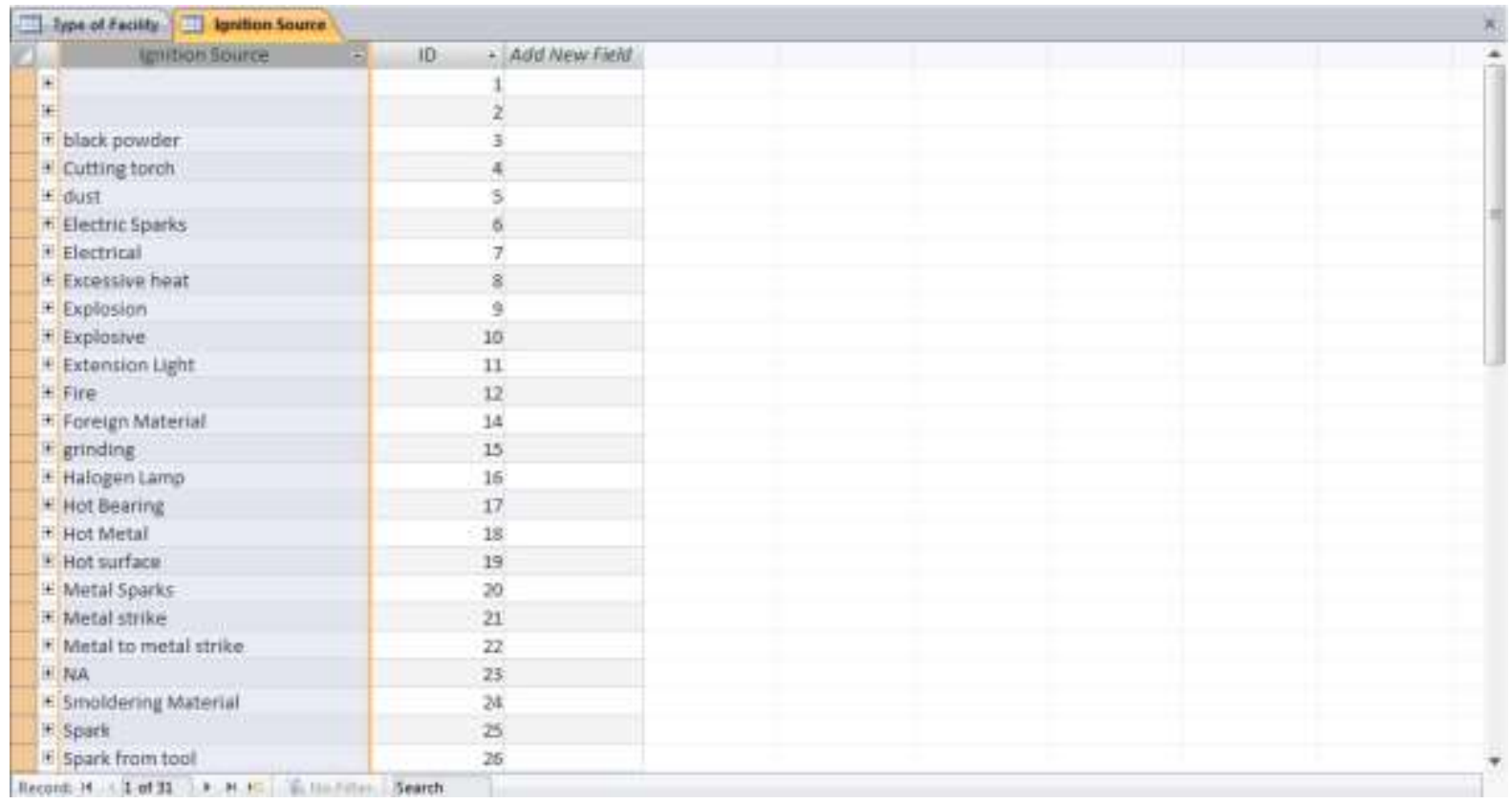

Figure 4: Ignition Sources Summary

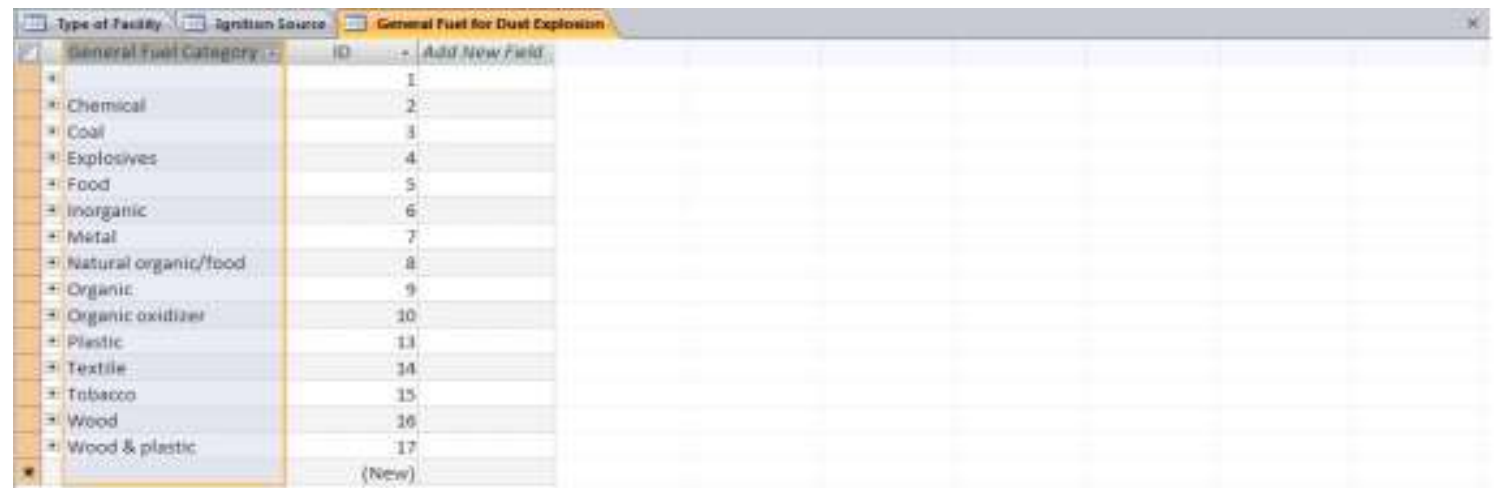

Figure 5: General Fuels Summary 
INTERNATIONAL JOURNAL OF ACADEMIC RESEARCH IN BUSINESS AND SOCIAL SCIENCES

Vol. 9, No. 11, November, 2019, E-ISSN: 2222-6990 @ 2019 HRMARS

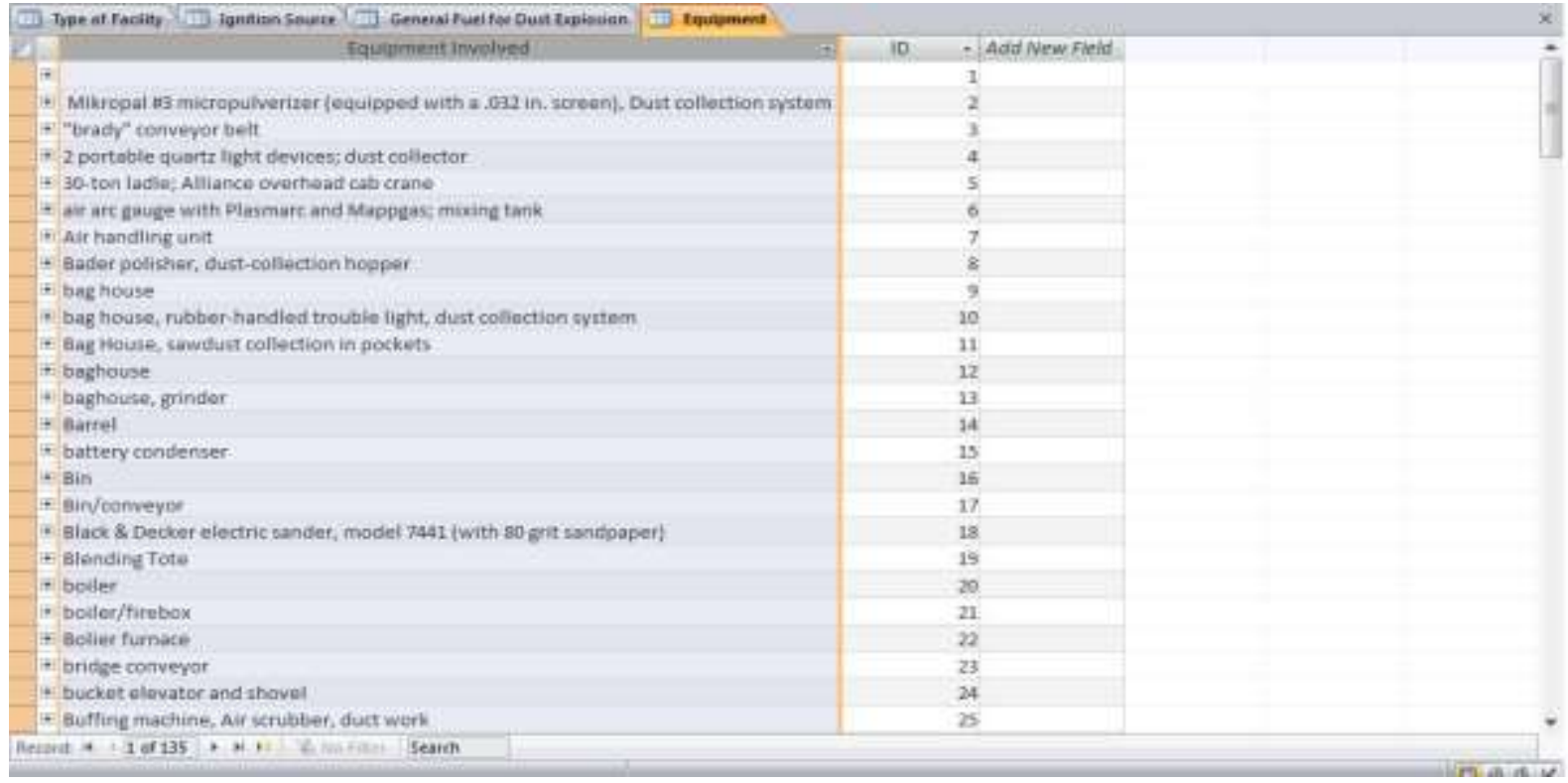

Figure 6: Types of equipment Summary

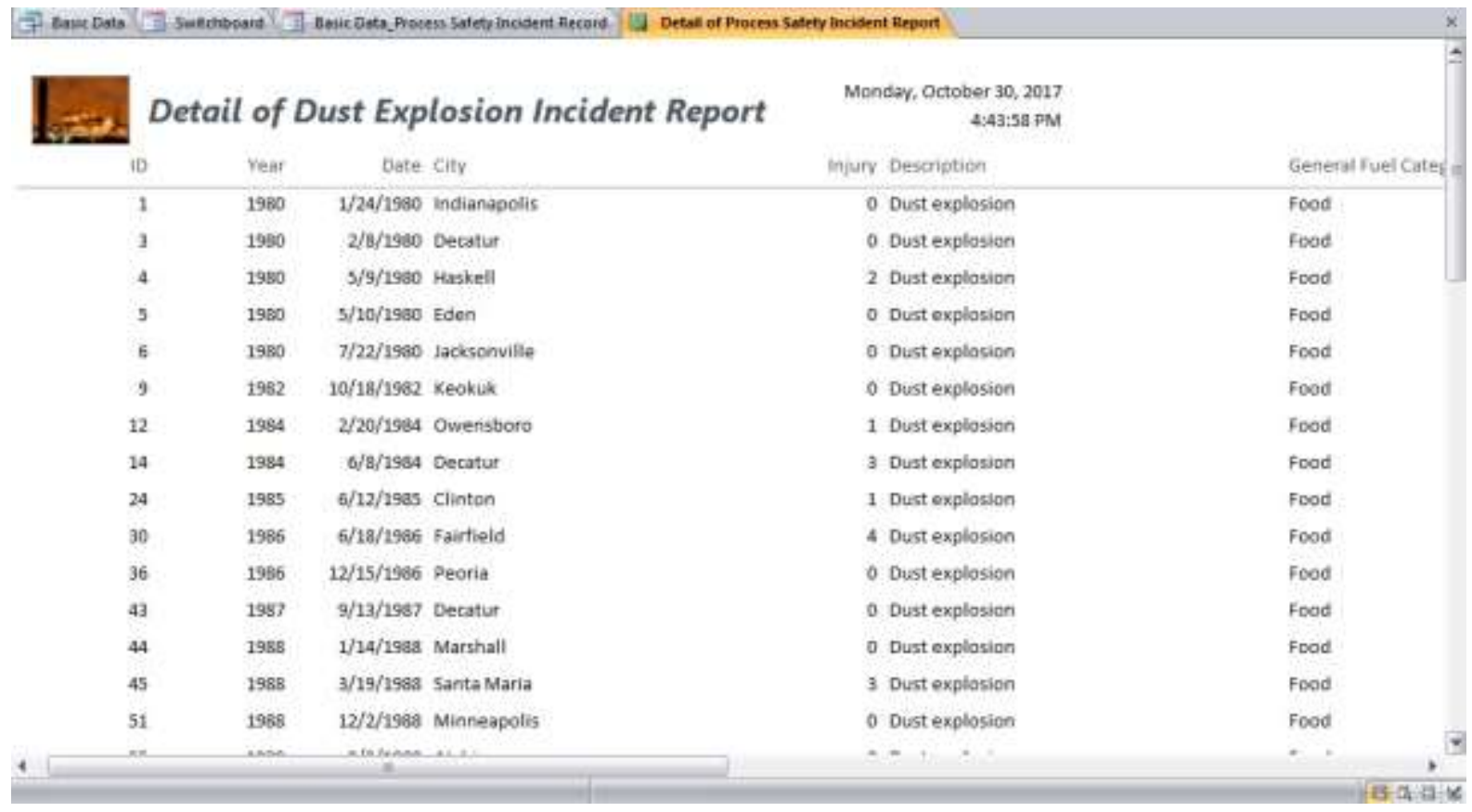

Figure 7: Dust Explosion Incident Summary

\section{Conclusions}

As a summary and to conclude the importance of the development of Malaysia database accident majoring in Process Safety as in the review dust explosion as a start. This paper 
highlighting the major findings associated with past accident analysis and other resources that study the same area.

This paper then presents a new system database comprising Malaysia trend of accident related to dust explosion and covering all related event that already being tabulated in the same framework. The author intention is to update UMP-DEx once every year and make it available to users at no charges. UMP will become Excellent Centre for Process Safety managing and discussing on issues and the ways to mitigate the reoccurrences of the accident as UMP being relevant located near Gebeng Industrial Area.

\section{Acknowledgement}

I would like to thanks to all that have given support through this research works that help in making UMP-DEx as the reality in the sharing with University Malaysia Pahang and Industries that handling combustible dust in their operations.

\section{Corresponding Author}

Mohd Azimie Bin Ahmad, PhD postgraduate in University Malaysia Pahang, Malaysia, email mohdazimie@gmail.com. Address No 183, Lorong 11, Taman Jambu Delima, 26600, Pekan, Pahang Darul Makmur.

\section{References}

Abbasi, T., \& Abbasi, S. A. (2005). The expertise and the practice of loss prevention in the Indian process industry some pointers for the third world. Process Safety and Environmental Protection, 83(5B), 413-420.

Abbasi, T., \& Abbasi, S. A. (2007a). Accidental risk of superheated liquids and a framework for predicting the superheat limit. Journal of Loss Prevention in the Process Industries, 20(2), 165-181.

Abbasi, T., \& Abbasi, S. A. (2007b). The boiling liquid expanding vapour explosion (BLEVE): mechanism, consequence assessment, management. Journal of Hazardous Materials, 141(3), 489-519.

Abbasi, T., \& Abbasi, S. A. (2007c). Dust explosions e cases, causes, consequences, and control. Journal of Hazardous Materials, 140(1-2), 7-44.

Abbasi, T., \& Abbasi, S. A. (2008). The boiling liquid expanding vapour explosion (BLEVE) is fifty. And lives on! Journal of Loss Prevention in the Process Industries, 21(4), 485-487.

Abdolhamidzadeh, B., Abbasi, T., Rashtchian, D., \& Abbasi, S. A. (2010). Domino effect in processindustry accidents e an inventory of past events and identification of some patterns. Journal of Loss Prevention in the Process Industries, doi:10.1016/j.jlp.2010.06.013.

Brambilla, S., \& Manca, D. (2010). The Viareggio LPG railway accident: event reconstruction and modelling. Journal of Hazardous Materials, 182(1-3), 346-357.

Carol, S., Vilchez, J. A., \& Casal, J. (2002). Study of the severity of industrial accidents with hazardous substances by historical analysis. Journal of Loss Prevention in the Process Industries, 15(6), 517-524. 
Clini, F., Darbra, R. M., \& Casal, J. (2010). Historical analysis of accidents involving the domino effect. Chemical Engineering, 19, 335-340.

Gerboni, R., \& Salvador, E. (2009). Hydrogen transportation systems: elements of risk analysis. Energy, 34(12), 2223-2229.

Gomez-Mares, M., Zarate, L., \& Casal, J. (2008). Jet fires and the domino effect. Fire Safety Journal, 43(8), 583-588.

Guo, C. (2002). The estimation of the probable number of fatalities in accidental explosion based on historical accident analysis. In Progress in safety science and technology, Taian (91-96).

Khan, F. I., \& Abbasi, S. A. (1998). Techniques and methodologies for risk analysis in chemical process industries. Journal of Loss Prevention in the Process Industries, 11, 261-277.

Khan, F. I., \& Abbasi, S. A. (1999). Major accidents in process industries and an analysis of causes and consequences. Journal of Loss Prevention in the Process Industries, 12(5), 361-378.

Manca, D., \& Brambilla, S. (2010). Complexity and uncertainty in the assessment of the Viareggio LPG railway accident. Journal of Loss Prevention in the Process Industries, 23(5), 668-679.

Montiel, H., Vílchez, J. A., Arnaldos, J., \& Casal, J. (1996). Historical analysis of accidents in the transportation of natural gas. Journal of Hazardous Materials, 51(1-3), 77-92.

Planas-Cuchi, E., Montiel, H., \& Casal, J. (1997). A survey of the origin, type and consequences of fire accidents in process plants and in the transportation of hazardous materials. Process Safety and Environmental Protection, 75(1), 3-8.

Renni, E., Krausmann, E., \& Cozzani, V. (2010). Industrial accidents triggered by lightning. Journal of Hazardous Materials, 184(1-3), 42-48. 